\title{
Difficulties Comparatively Testing Total Loanable Funds and Endogenous Loanable Funds Only in the Same Model
}

As another test, we had wished to test two variants of the modified crowd out variables, $(\mathrm{S}+\mathrm{FB})-(\mathrm{Tr}+\mathrm{A})$ and $(\mathrm{Tr}+\mathrm{A})$, by inserting both of them in the same standard consumption and investment models to see which proved statistically significant (or more significant). This would show us which type of change in loanable funds, endogenous or exogenous, was had the largest and most systematic effect in reducing crowd out. The variables to be tested were $\mathrm{T}+(\mathrm{S}+\mathrm{FB}-\mathrm{Tr}-\mathrm{A}), \mathrm{T}+(\mathrm{Tr}+\mathrm{A}), \mathrm{G}-(\mathrm{S}$ + FB-Tr-A), and $\mathrm{G}-(\operatorname{Tr}+\mathrm{A})$. We wished to determine which type of loanable funds modification of deficit effects explained the most variance. Unfortunately, the variables were so highly multicollinear the regression would not run. Hence, for results showing the effect of each of these two modifications on consumption and investment, we refer the reader to Chapters 28, 31 and 29 where as separate, stand-alone variables, they are tested in models without any modification of the deficit variables $(\mathrm{T}$, $\mathrm{G})$ by them. Those tests indicate both the endogenous and exogenous parts of the loanable funds pool can play a role in offsetting crowd out. For the exogenous part (FR open market security purchases), this was especially true in the early QE years included in the sample.

(C) The Author(s), under exclusive license to Springer Nature 